\title{
ELECTRICAL PROPERTIES OF EPITAXIAL ALUMINIUM FILMS
}

\author{
E. DOBIERZEWSKA-MOZRZYMAS and F. WARKUSZ \\ Institute of Physics, Wrockaw Technical University, \\ Wybrzeze Wyspiańskiego 27, 50-370 Wroctaw, Poland
}

(Received May 23, 1978; in final form August 10, 1978)

\begin{abstract}
The resistivity of monocrystalline Al films was measured and compared with the resistivity calculated in terms of the function which takes into account both the external and the internal size effects. A comparison of the theoretical and experimental curves shows that the specular reflection coefficient $(p)$ is small, while the coefficient of electron transmission through the grain boundary $(r)$ increases with increasing film thickness.
\end{abstract}

\section{INTRODUCTION}

The resistivity of metal films is known to be thickness and grain-size dependent. ${ }^{1-3}$ Based on Fuchs's model of electron scattering, ${ }^{4}$ Mayadas and Shatzkes ${ }^{2}$ have developed a function which takes into account the influence of both external and internal size effects on the resistivity of the film. Using the layer model proposed by Cottey ${ }^{5}$ the scattering function $W(\mu, \nu)^{3}$ was derived, which describes the dependence of the film resistivity on film thickness and grain diameter. The comparison of experimental resistivities and the resistivities calculated in terms of the Mayadas-Shatzkes grain-boundary scattering function and Cottey's surface scattering function is presented elsewhere by the authors. ${ }^{6}$ In this paper the function $W(\mu, \nu)$ is used to calculate the resistivity vs. grain diameter $(b)$ for two series of $\mathrm{Al}$ films exhibiting various thicknesses $(a)$. The accepted values of $a$ and $b$ were obtained from measurements. Theoretical and experimental curves are compared.

\section{THEORY}

Considering the electron scattering on the external surfaces and on the grain boundaries the resistivity of the film $\left(\rho_{f}\right)$ can be represented as follows

$$
\rho_{f}=\frac{\rho_{B}}{W(\mu, \nu)}
$$

where $\rho_{B}$ denotes the resistivity of the bulk material, and $W(\mu, \nu)$ refers to the function derived by
Warkusz ${ }^{3}$ which depends on the film thickness $(a)$, on the fraction of electrons specularly scattered at the film surface $(p)$, on the grain diameter $(b)$, on the coefficient of electron transmission through the grain boundary $(r)$ and finally on the electron mean free path $\lambda$, whereas

$$
\mu=\frac{a}{\lambda \ln 1 / p}
$$

and

$$
\nu=\frac{b}{\lambda \ln 1 / r}
$$

Depending on the parameters $\mu$ and $\nu$, the function $W(\mu, \nu)$ takes the following form:

$$
\begin{aligned}
& W_{1}(\mu, \nu) \text { if } \mu \neq 1, \frac{1}{\mu^{2}}+\frac{1}{\nu^{2}}>1 \\
& W_{2}(1, \nu) \text { if } \mu=1, \frac{1}{\mu^{2}}+\frac{1}{\nu^{2}}>1 \\
& W_{3}(\mu, \nu) \text { if } \frac{1}{\mu^{2}}+\frac{1}{\nu^{2}}=1 \\
& W_{4}(\mu, \nu) \text { if } \frac{1}{\mu^{2}}+\frac{1}{\nu^{2}}<1
\end{aligned}
$$

$W_{1}, W_{2}, W_{3}$ and $W_{4}$ are given by Warkusz. ${ }^{3}$

The extreme terms of these functions required in our calculations are presented below. If the film thickness is sufficiently high $(a / \lambda \rightarrow \infty)$ or if $p \rightarrow 1$, then in 
terms of Eq. (2) $\mu \rightarrow \infty$ and $W_{1}(\mu, \nu)=F_{1}(\nu)$ or $W_{4}(\mu, \nu)=F_{2}(\nu)$ where

$$
\begin{gathered}
F_{1}(\nu)=\frac{3}{2} \nu\left(\frac{\pi}{4}-\nu+\frac{\pi}{2} \nu^{2}+\frac{\nu^{3}}{\sqrt{1-\nu^{2}}} \ln \right. \\
\left.\frac{\nu}{1+\sqrt{1-\nu^{2}}}\right) \text { for } \nu<1 \\
F_{2}(\nu)=\frac{3}{2} \nu\left(\frac{\pi}{4}-\nu+\frac{\pi}{2} \nu^{2}-\frac{\nu^{3}}{\sqrt{\nu^{2}-1}}\right. \\
\left.\arcsin \sqrt{1-1 / \nu^{2}}\right) \text { for } \nu>1
\end{gathered}
$$

If the films of interest exhibit a large grain size $(b / \lambda \rightarrow \infty)$ or if $r \rightarrow 1$, then $W_{1}(\mu, \nu)=W_{4}(\mu, \nu)=F(\mu)$ where

$$
F(\mu)=\frac{3}{2} \mu\left\{\mu-\frac{1}{2}+\left(1-\mu^{2}\right) \ln \left(1+\frac{1}{\mu}\right)\right\}
$$

For a sufficiently thick film with large grain size

$$
\lim _{\substack{\mu \rightarrow \infty \\ \nu \rightarrow \infty}} W(\mu, \nu)=1 .
$$

The product $F(\mu) \cdot F_{2}(\nu)$ also tends to unity,

$$
\lim _{\substack{\mu \rightarrow \infty \\ \nu \rightarrow \infty}} F(\mu) F_{2}(\nu)=1 .
$$

Hence, $W(\mu, \nu)$ can be replaced by $F(\mu) \cdot F_{2}(\nu)$ and Eq. (1) becomes

$$
\rho_{f}=\frac{\rho_{B}}{F(\mu) F_{2}(\nu)}
$$

Considering Eq. (1) and Eq. (8) the $\rho_{f} / \rho_{B}$ ratio is calculated as a function of $a / \lambda$ and $b / \lambda$ for the given parameters $p$ and $r$. The results are listed in Tables I and II. It is seen that $\rho_{f} / \rho_{B}$ tends to unity, if the values of $a / \lambda$ and $b / \lambda$ are high and if $p$ or $r$ approaches unity. Then, the values of $\rho_{f} / \rho_{B}$ calculated in terms of Eq. (1) and Eq. (8) are insignificantly different.

\section{EXPERIMENTAL}

Monocrystalline and textured $\mathrm{Al}$ films were obtained by using the method reported elsewhere by the authors, ${ }^{7,8}$ and by applying a parallel or perpendicular electric field during evaporation. ${ }^{9}$ Resistivity measurements were carried out for films of the

\begin{tabular}{|c|c|c|c|c|c|c|c|c|c|c|c|c|}
\hline \multirow{2}{*}{$b / \lambda$} & \multicolumn{12}{|c|}{$a / \lambda$} \\
\hline & 0.1 & $\begin{array}{l}\delta \\
{[\%]}\end{array}$ & 0.5 & $\begin{array}{l}\delta \\
{[\%]}\end{array}$ & 1 & $\begin{array}{l}\delta \\
{[\%]}\end{array}$ & 2 & $\begin{array}{l}\delta \\
{[\%]}\end{array}$ & 5 & $\begin{array}{l}\delta \\
{[\%]}\end{array}$ & 10 & $\begin{array}{l}\delta \\
{[\%]}\end{array}$ \\
\hline 0.1 & $\begin{array}{l}12.450 \\
31.244 *\end{array}$ & 150.9 & $\begin{array}{c}8.321 \\
13.415^{*}\end{array}$ & 61.2 & $\begin{array}{c}7.675 \\
10.503^{*}\end{array}$ & 36.8 & $\begin{array}{l}7.325 \\
8.848^{*}\end{array}$ & 20.8 & $\begin{array}{l}7.104 \\
7.750^{*}\end{array}$ & 9.1 & $\begin{array}{l}7.028 \\
7.361^{*}\end{array}$ & 4.7 \\
\hline 0.5 & $\begin{array}{l}6.454 \\
9.911 *\end{array}$ & 53.5 & $\begin{array}{l}3.321 \\
4.255^{*}\end{array}$ & 28.1 & $\begin{array}{l}2.811 \\
3.332 *\end{array}$ & 18.5 & $\begin{array}{l}2.525 \\
2.807^{*}\end{array}$ & 11.2 & $\begin{array}{l}2.338 \\
2.458^{*}\end{array}$ & 5.1 & $\begin{array}{l}2.273 \\
2.335^{*}\end{array}$ & 2.7 \\
\hline 1 & $\begin{array}{l}5.539 \\
7.214^{*}\end{array}$ & 30.2 & $\begin{array}{l}2.646 \\
3.097 *\end{array}$ & 17.0 & $\begin{array}{l}2.174 \\
2.425^{*}\end{array}$ & 11.5 & $\begin{array}{l}1.907 \\
2.043^{*}\end{array}$ & 7.1 & $\begin{array}{l}1.732 \\
1.789 *\end{array}$ & 3.3 & $\begin{array}{l}1.670 \\
1.699 *\end{array}$ & 1.7 \\
\hline 2 & $\begin{array}{l}5.040 \\
5.861 *\end{array}$ & 16.3 & $\begin{array}{l}2.296 \\
2.517 *\end{array}$ & 9.6 & $\begin{array}{l}1.847 \\
1.970 *\end{array}$ & 6.7 & $\begin{array}{l}1.593 \\
1.660^{*}\end{array}$ & 4.2 & $\begin{array}{l}1.426 \\
1.454 *\end{array}$ & 1.9 & $\begin{array}{l}1.366 \\
1.381 *\end{array}$ & 1.1 \\
\hline 5 & $\begin{array}{l}4.720 \\
5.043 *\end{array}$ & 6.8 & $\begin{array}{l}2.079 \\
2.165^{*}\end{array}$ & 4.1 & $\begin{array}{l}1.647 \\
1.695 *\end{array}$ & 2.9 & $\begin{array}{l}1.402 \\
1.428 *\end{array}$ & 1.9 & $\begin{array}{l}1.240 \\
1.251^{*}\end{array}$ & 0.89 & $\begin{array}{l}1.182 \\
1.188^{*}\end{array}$ & 0.50 \\
\hline 10 & $\begin{array}{l}4.609 \\
4.769 *\end{array}$ & 3.5 & $\begin{array}{l}2.005 \\
2.048^{*}\end{array}$ & 2.1 & $\begin{array}{l}1.579 \\
1.603 *\end{array}$ & 1.5 & $\begin{array}{l}1.338 \\
1.351^{*}\end{array}$ & 0.97 & $\begin{array}{l}1.178 \\
1.183^{*}\end{array}$ & 0.42 & $\begin{array}{l}1.121 \\
1.123^{*}\end{array}$ & 0.23 \\
\hline
\end{tabular}
following thicknesses: $a=600 \AA \pm 150 \AA$ and $2000 \AA \leqslant a \leqslant 3800 \AA$; the measuring accuracy being of the order of $10 \%$. To determine the average grain diameter, the size of about 300 grains on given fragments of the sample was established from electron micrographs. The grain diameters of the series of thin films $(0.7 \leqslant a / \lambda \leqslant 1.25)$ were between $1300 \AA$ and $4000 \AA$, and the grain diameters of the series of thicker films $(3.0 \leqslant a / \lambda \leqslant 6.5)$ fell between

TABLE I

$\rho_{f} / \rho_{B}$ calculated from Eq. (1) and Eq. (8) (with asterisk) for $p=0.2$ and $r=0.5 ; \delta$ is the percent relative error. 
TABLE II

$\rho_{f} / \rho_{B}$ calculated from Eq. (1) and Eq. (8) (with asterisk) for $p=0.5$ and $r=0.5 ; \delta$ is the percent relative error.

\begin{tabular}{|c|c|c|c|c|c|c|c|c|c|c|c|c|}
\hline \multirow{2}{*}{$b / \lambda$} & \multicolumn{12}{|c|}{$a / \lambda$} \\
\hline & 0.1 & $\begin{array}{l}\delta \\
{[\%]}\end{array}$ & 0.5 & $\begin{array}{l}\delta \\
{[\%]}\end{array}$ & 1 & $\begin{array}{l}\delta \\
{[\%]}\end{array}$ & 2 & $\begin{array}{l}\delta \\
{[\%]}\end{array}$ & 5 & $\begin{array}{l}\delta \\
{[\%]}\end{array}$ & 10 & $\begin{array}{l}\delta \\
{[\%]}\end{array}$ \\
\hline 0.1 & $\begin{array}{c}9.657 \\
19.226 *\end{array}$ & 99.1 & $\begin{array}{c}7.580 \\
10.058 *\end{array}$ & 32.7 & $\begin{array}{l}7.275 \\
8.598 *\end{array}$ & 18.2 & $\begin{array}{l}7.116 \\
7.813^{*}\end{array}$ & 9.8 & $\begin{array}{l}7.018 \\
7.305^{*}\end{array}$ & 4.1 & $\begin{array}{l}6.984 \\
7.132 *\end{array}$ & 2.1 \\
\hline 0.5 & $\begin{array}{l}4.346 \\
6.099 *\end{array}$ & 40.3 & $\begin{array}{l}2.734 \\
3.191 *\end{array}$ & 16.7 & $\begin{array}{l}2.483 \\
2.727^{*}\end{array}$ & 9.8 & $\begin{array}{l}2.348 \\
2.478^{*}\end{array}$ & 5.5 & $\begin{array}{l}2.264 \\
2.317 *\end{array}$ & 2.3 & $\begin{array}{l}2.235 \\
2.262 *\end{array}$ & 1.2 \\
\hline 1 & $\begin{array}{l}3.592 \\
4.439 *\end{array}$ & 23.6 & $\begin{array}{l}2.102 \\
2.222^{*}\end{array}$ & 10.5 & $\begin{array}{l}1.868 \\
1.985^{*}\end{array}$ & 6.3 & $\begin{array}{l}1.741 \\
1.804 *\end{array}$ & 3.6 & $\begin{array}{l}1.661 \\
1.687 *\end{array}$ & 1.5 & $\begin{array}{l}1.634 \\
1.646 *\end{array}$ & 0.78 \\
\hline 2 & $\begin{array}{l}3.192 \\
3.607^{*}\end{array}$ & 13.0 & $\begin{array}{l}1.779 \\
1.887^{*}\end{array}$ & 6.1 & $\begin{array}{l}1.556 \\
1.613^{*}\end{array}$ & 3.6 & $\begin{array}{l}1.435 \\
1.466^{*}\end{array}$ & 2.1 & $\begin{array}{l}1.358 \\
1.370^{*}\end{array}$ & 0.92 & $\begin{array}{l}1.331 \\
1.338^{*}\end{array}$ & 0.50 \\
\hline 5 & $\begin{array}{l}2.941 \\
3.103 *\end{array}$ & 5.5 & $\begin{array}{l}1.582 \\
1.623^{*}\end{array}$ & 2.6 & $\begin{array}{l}1.366 \\
1.388^{*}\end{array}$ & 1.6 & $\begin{array}{l}1.249 \\
1.261^{*}\end{array}$ & 0.97 & $\begin{array}{l}1.174 \\
1.179 *\end{array}$ & 0.44 & $\begin{array}{l}1.148 \\
1.151^{*}\end{array}$ & 0.28 \\
\hline 10 & $\begin{array}{l}2.854 \\
2.935^{*}\end{array}$ & 2.8 & $\begin{array}{l}1.515 \\
1.535^{*}\end{array}$ & 1.3 & $\begin{array}{l}1.302 \\
1.312 *\end{array}$ & 0.81 & $\begin{array}{l}1.186 \\
1.193^{*}\end{array}$ & 0.56 & $\begin{array}{l}1.113 \\
1.115^{*}\end{array}$ & 0.19 & $\begin{array}{l}1.087 \\
1.089 *\end{array}$ & 0.15 \\
\hline
\end{tabular}

$2000 \AA$ and $18000 \AA$. Resistivity measurements for films drawn from the vacuum chamber were performed at room temperature with the use of the four-point microprobe method.

\section{DISCUSSION OF RESULTS AND CONCLUSIONS}

Figure 1 represents the experimental curves (full lines) illustrating the dependence of $\rho_{f} / \rho_{R}$ on $b / \lambda$ for two groups of the parameters $a / \lambda$. Using Eq. (1) the theoretical curves (dotted lines) are calculated with the assumption that $\lambda=600 \AA$ and $\rho_{B}=2.5 \times 10^{-6} \Omega \mathrm{cm}$. A qualitative agreement between the theoretical and experimental results if found. The resistivity of $\mathrm{Al}$ films is grain size dependent. This dependence, however, is more pronounced in thinner films. The values of resistivity which correspond to the same grain diameter but various film thicknesses show considerable differences. For thin $\mathrm{Al}$ films good

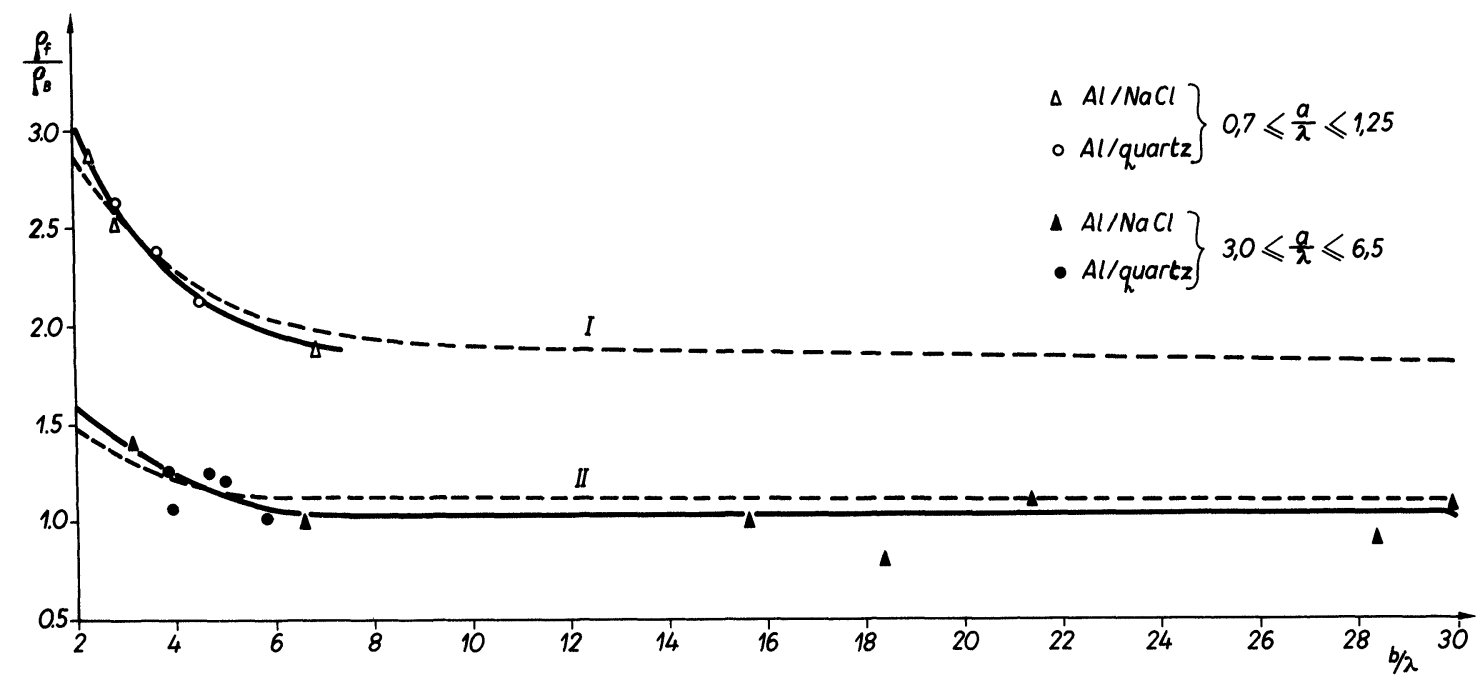

FIGURE $1 \rho_{f} / \rho_{B}$ versus $b / \lambda$ curves. Theoretical curves (dotted lines) are calculated from Eq. (1) with $p=0.1$, $r=0.1\left(R^{*}=0.58\right)$ and $a / \lambda=1$ for curve I, and $p=0.1, r=0.5\left(R^{*}=0.30\right)$ and $a / \lambda=5$ for curve II. 
agreement between the theoretical and experimental curves is obtained when both $p$ and $r$ are assumed to be equal to 0.1 . For thick films the accepted $p$ and $r$ values are 0.1 and 0.5 , respectively. It follows from Figure 1 that the specular reflection coefficient $p$ remains small $(p=0.1)$ both for thin and thick films. The coefficient of electron transmission through the grain boundary $r$ shows lower values $(r=0.1)$ for thin films and higher values $(r=0.5)$ for thick films.

A relationship is found between the parameter $r$ and the grain boundary scattering coefficient $R^{* 3}$, where $R^{*}$ is defined as the ratio of the number of electrons scattered by the boundary, compared with the total number of electrons impinging on the boundary.

$$
\frac{R^{*}}{1-R^{*}}=0.62 \ln \frac{1}{r}
$$

Thus, in the case of thin films $R^{*} \approx 0.58$, and in the case of thick films $R^{*} \approx 0.30$. Similar results for $\mathrm{Al}$ films are reported by Tellier and Tosser ${ }^{10}$ and by Mayadas and Shatzkes. ${ }^{2}$ For $110 \AA \leqslant a \leqslant 900 \AA$ thicknesses, $R^{*}=0.519^{10}$ and for significantly thicker films $R^{*}=0.17 .^{2}$

\section{ACKNOWLEDGEMENTS}

The study was supported by the Institute of Physics, University of Warsaw M.R. 1-5. The authors are indebted to Professor C. Wesołowska, Wrocław Technical University, for discussion and encouragement. Thanks are also due to Dr. S. Lewanowicz, University of Wrocław, for computer calculations.

\section{REFERENCES}

1. F. Warkusz, Electrocomp. Sci. and Technol., (1978) in press.

2. A. F. Mayadas and M. Shatzkes, Phys. Rev. B., 1, 1382 (1970).

3. F. Warkusz, Acta Phys. Pol., A 54, (1978).

4. K. Fuchs, Proc. Cambridge Phil. Soc., 34, 100 (1938).

5. A. A. Cottey, Thin Solid Films, 1, 297 (1968).

6. E. Dobierzewska-Mozrzymas, and F. Warkusz, Thin Solid Films, 43, 267 (1977).

7. E. Dobierzewska-Mozrzymas, Acta Phys. Pol., A 47, 93, (1975).

8. E. Dobierzewska-Mozrzymas, T. Ohly and F. Warkusz, J. Cryst. Grow., 32, 129 (1976).

9. E. Dobierzewska-Mozrzymas, Kom. Inst. Fiz. Pol. Wrock. Nr., 301 (1975).

10. C. Tellier and A. Tosser, Thin Solid Films, 37, 207 (1976). 

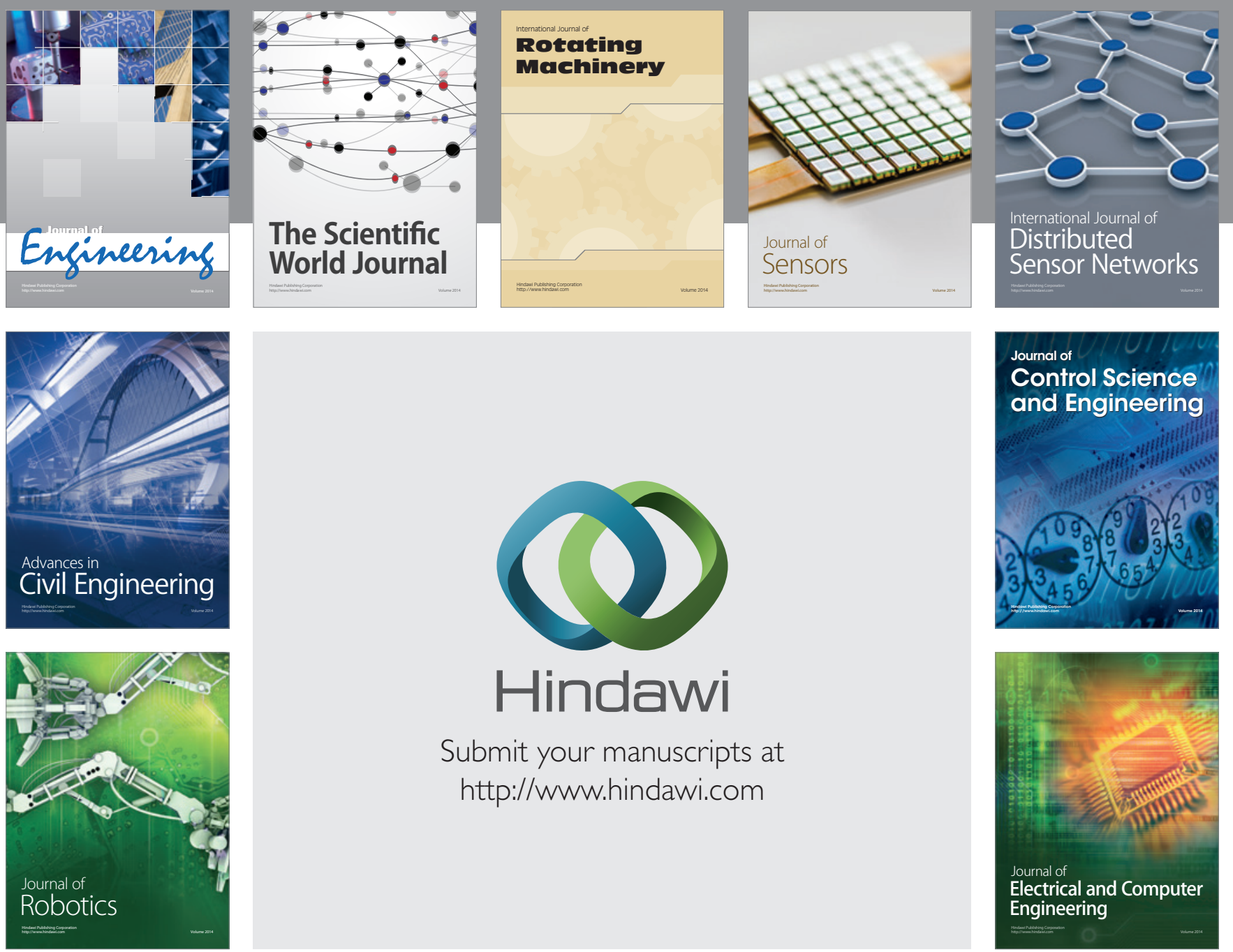

Submit your manuscripts at

http://www.hindawi.com
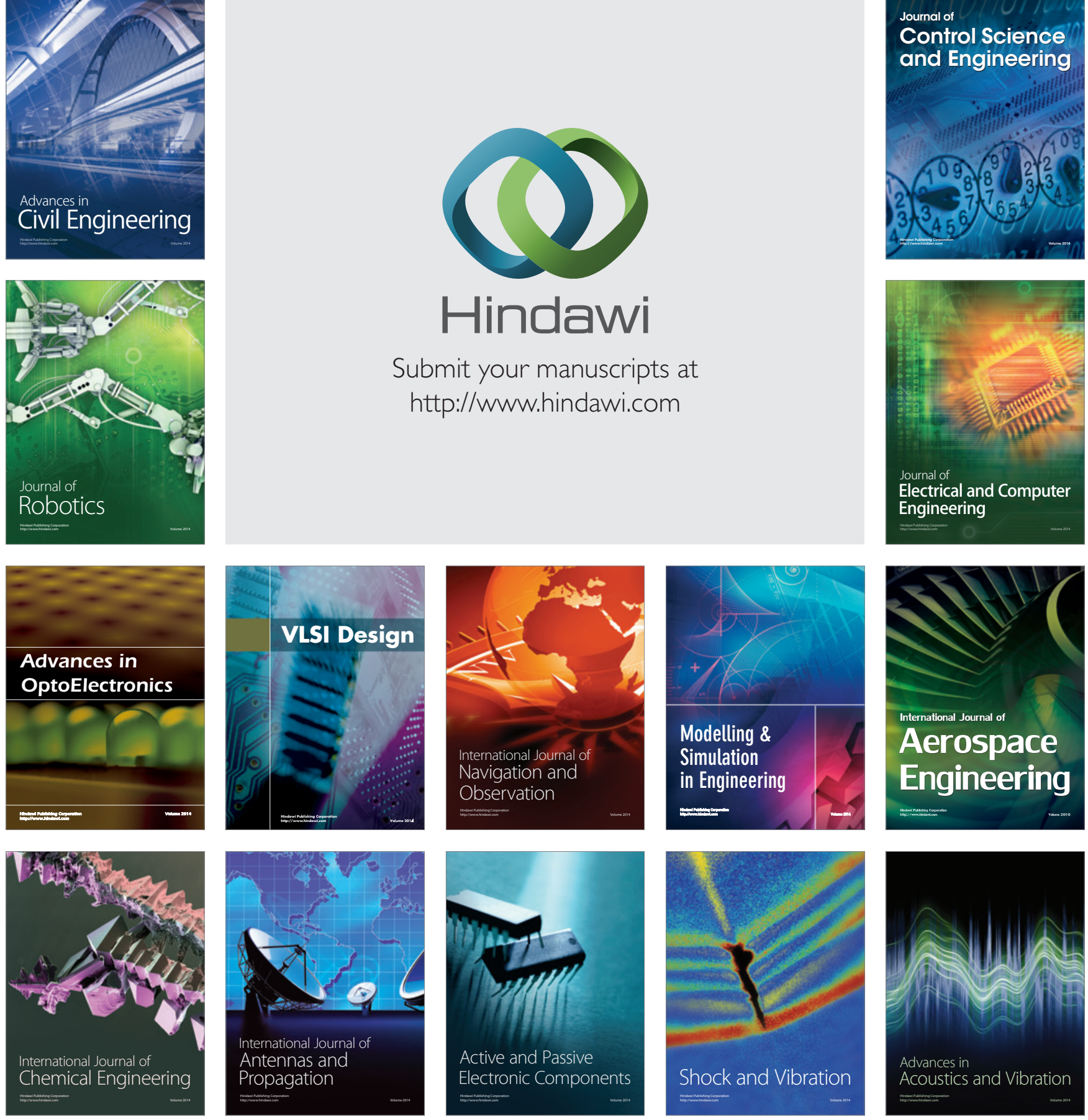